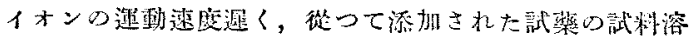

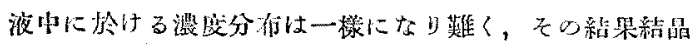

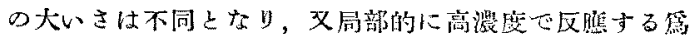
め歪んだ結晶を生じその第め溶液中心成分が結聂の生成

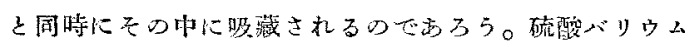
は溶解度小さく镂つて添加速度大なる特は紀昆核の生成

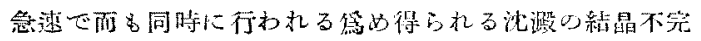

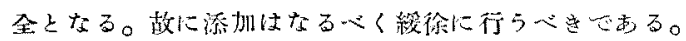

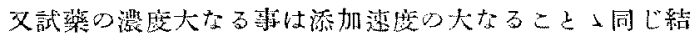
果て溶液內に於ける反焦が局部的心不均一に行われる䍃 め生成沈澱の結晶は整つたるのが得落倠いと考えられる。

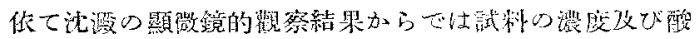

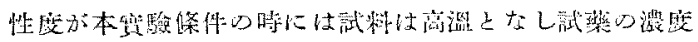

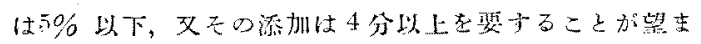

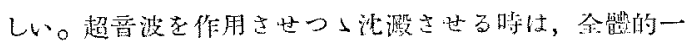

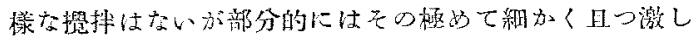

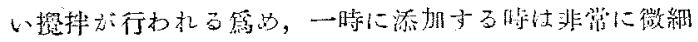

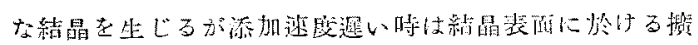

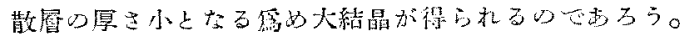

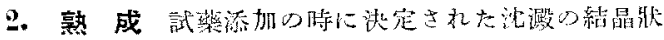

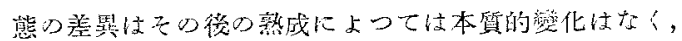
只僅かな成長改び琵合等が行わ机るかみです。故に沈

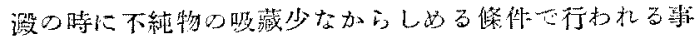

が必要である。滋浸による䓡成洁結晶狀態上り見る洔少

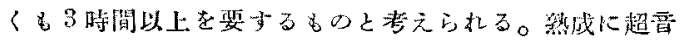
没を適用する時は，結鼠口溶解が著しく促進些られ，小

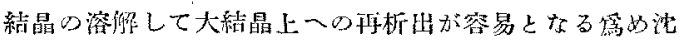

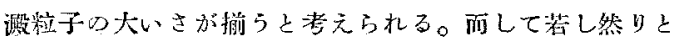

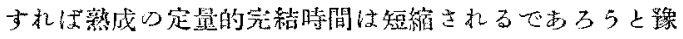

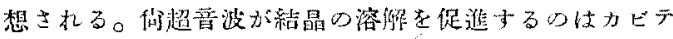
一ションによるを云われている゙。

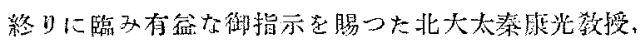

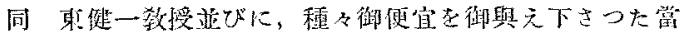

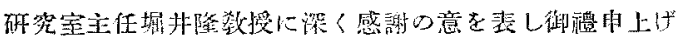
5。

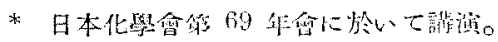

\section{一交献 -}

1) 高木, 中野，本野，日化，71，65 (1949)。

2) S. Popoff and W. Neuman, Fut. Eng. Chem. Anal. Ed., Q, 45 (1430).

3) D. Balarew, "Der Disperse Bau der Festen Systeme." \$. 79, Leipzig (1939).

4) Ardagh, R. E. Richardson, L. A. Richardson and Humber, I. Soc. Chem. Ind, 5s, 1035 (1984).

5) 白石, 露化, 11, 10 號， I (1943)。

\title{
䧼溶性鹽の溶解度に閣する研究（第７報）
}

\begin{abstract}
小晨

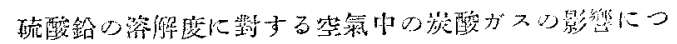
いて老综した。

\section{A. 實驗的考察}

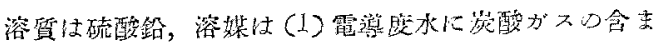

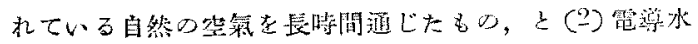

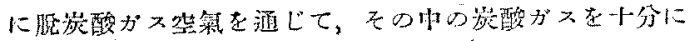

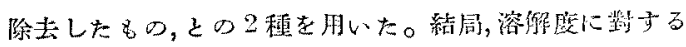

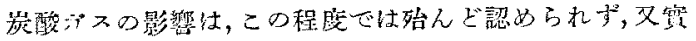

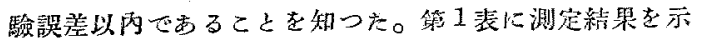
5o
\end{abstract}

\section{B. 理論的考察}

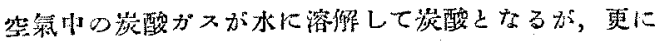

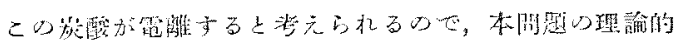

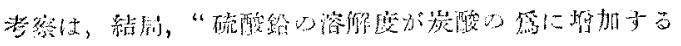

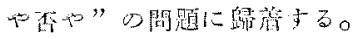

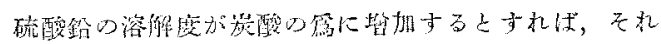

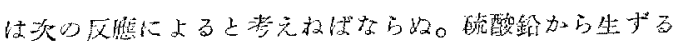

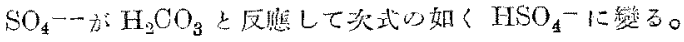

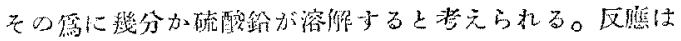

$$
\mathrm{SO}_{4}^{--}+\mathrm{H}_{2} \mathrm{CO}_{3} \rightleftarrows \mathrm{HCO}_{3}^{-}+\mathrm{HSO}_{4}^{-} \text {(I) }
$$

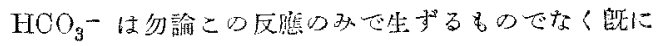

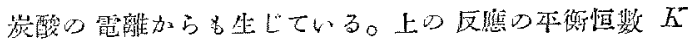
は次の如し。

$$
K=\frac{\left[\mathrm{HOO}_{3}-\right]\left[\mathrm{HSO}_{4}^{-}\right]}{\left[\mathrm{SO}_{4}^{-}-\right]\left[\mathrm{H}_{4} \mathrm{OO}_{3}\right]}=\frac{\left[\mathrm{HCO}_{3}^{-}\right]\left[\mathrm{H}^{+}\right]\left[\mathrm{HSO}_{4}^{-}\right]}{\left[\mathrm{SO}_{4}^{--}\right]\left[\mathrm{H}^{+}\right]\left[\mathrm{H}_{2} \mathrm{CO}_{3}\right]}
$$




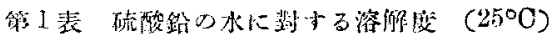

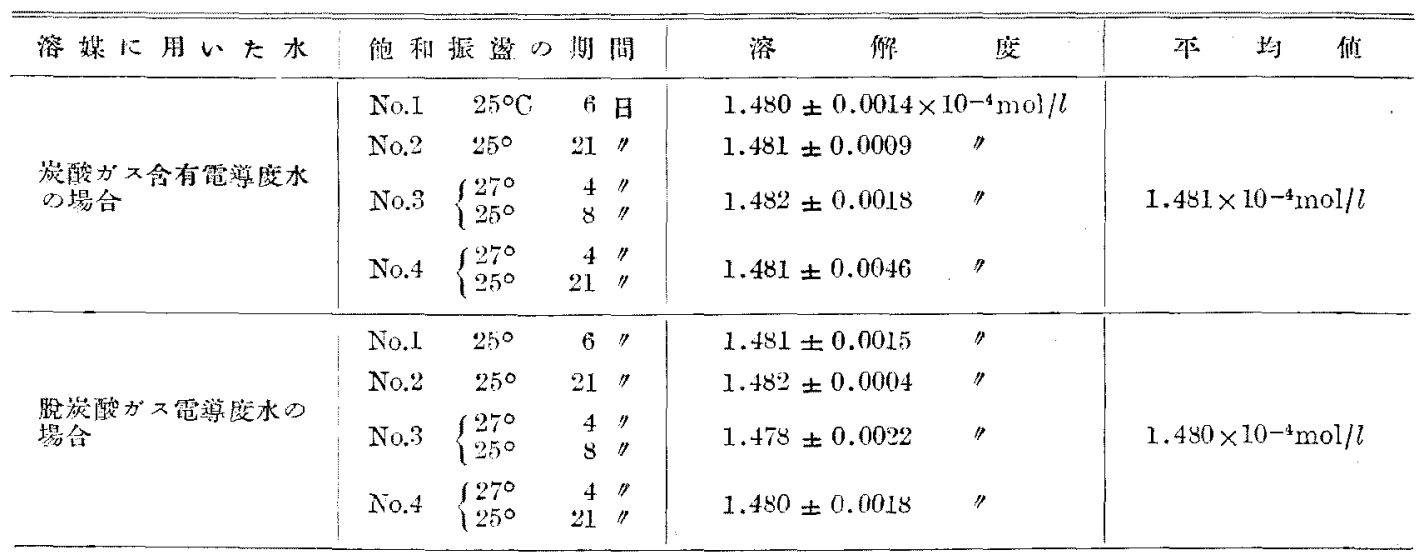

然るに, $\frac{\left[\mathrm{H}^{+}\right]\left[\mathrm{HOO}_{2}^{-}\right]}{\left[\mathrm{H}_{2} \mathrm{CO}_{3}\right]}=K_{1}^{-}=3.5 \times 10^{\cdots-7}$,

$$
\underset{\left[\mathrm{HSO}_{4}^{+}\right]}{\left[\mathrm{H}^{+}\right]\left[\mathrm{SO}_{4}^{--}\right]}=K_{2}\left(\mathrm{H}_{2} \mathrm{SO}_{4}\right)=3 \times 10^{-2}
$$

故に $K^{*}=\frac{K_{1}}{K_{2}}=\frac{3.5 \times 10^{-7}}{3 \times 10^{-2}}=1.2 \times 10^{-5}$

敞に车衡に些ける各イオンについて

$$
\begin{gathered}
{\left[\mathrm{HCO}_{3}^{-}\right]\left[\mathrm{HSO}_{4}^{--}\right]} \\
{\left[\mathrm{SO}_{4}^{-}-\right]\left[\mathrm{H}_{2} \mathrm{CO}_{3}\right]}
\end{gathered}=1.2 \times 10^{-5}
$$

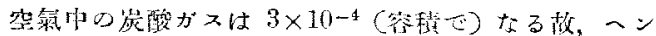

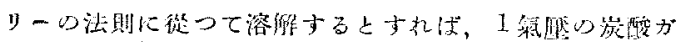

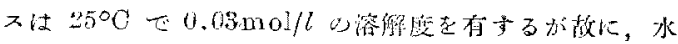

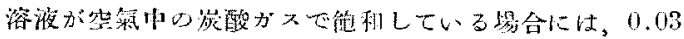

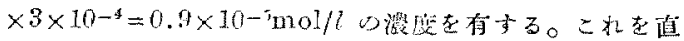

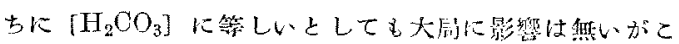

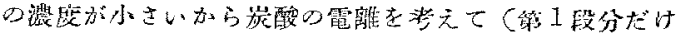

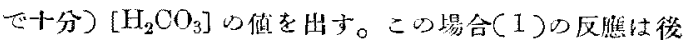

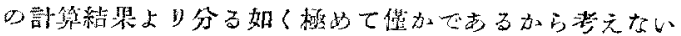
ぜ訫鼠する。

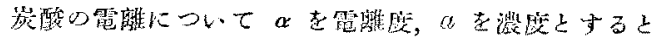

$$
\begin{aligned}
& \mathrm{H}_{2} \mathrm{CO}_{3} \rightleftarrows \mathrm{H}^{+}+\mathrm{HCO}_{3}-
\end{aligned}
$$

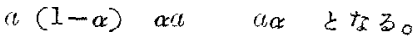

故保 $K_{4}=3.5 \times 10^{-7}=\frac{a \alpha a \alpha}{a(1-\alpha)}=\frac{a \alpha^{2}}{1-\alpha}$

$$
=\frac{0.9 \times 10^{-5} \alpha^{2}}{1-\alpha}
$$

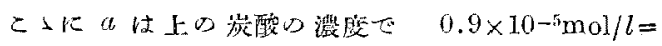
$\left[\mathrm{H}_{2} \mathrm{CO}_{3}\right]+\left[\mathrm{HCO}_{3}-\right]+\left[\mathrm{CO}_{3}-\cdots\right]$ 相賞するものであるが, [ $\left.\mathrm{HCO}_{3}^{-}\right],\left[\mathrm{CO}_{3}^{--}\right]$は小である加ら徦に $a=0.9 \times 10^{-5}$ として上式から $\alpha$ を求めると $\alpha=0.18$ となる。故に $\left[\mathrm{H}_{2} \mathrm{CO}_{3}\right]=0.9 \times 10^{-5} \times(1-0.18) \fallingdotseq 0.74 \times 10^{-5}$, 更K正磪

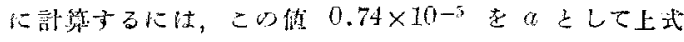

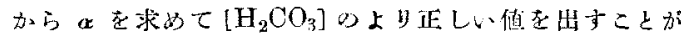

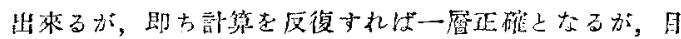
下゙の目的にはをこまさする必豚はない。

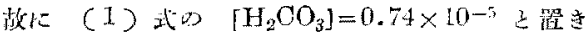

$$
\frac{\left[\mathrm{HOO}_{3}^{-}\right]\left[\mathrm{HSO}_{4}^{-]}\right.}{\left[\mathrm{SO}_{4}^{--}\right] \times 0.74 \times 10^{-5}}=1.2 \times 10^{-5}
$$$$
\left[\mathrm{HCO}_{3}-\right]\left[\mathrm{HSO}_{4}^{-}\right]=0.9 \times 10^{-19}
$$

$$
\left[\mathrm{SO}_{4}^{--}\right]
$$

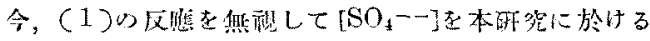

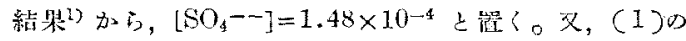
反照を考えに入机ると，反盟に上り幾分 $\mathrm{Pb}^{++}$加堆加与

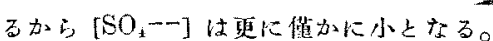

$$
\text { (3) מ. 万 } \begin{gathered}
\frac{\left[\mathrm{HOO}_{3}-\right]\left[\mathrm{HSO}_{4}^{-}\right]}{1.48 \times 10^{-4}}=0.9 \times 10^{-10} \\
{\left[\mathrm{HOO}_{3}-\left[\left[\mathrm{HSO}_{4}^{-}\right]=0.9 \times 10^{-10}\right.\right.} \\
\quad \times 1.48 \times 10^{-4}=1.34 \times 10^{-14}
\end{gathered}
$$

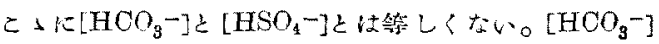

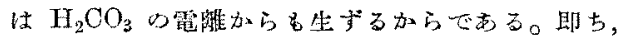
$\left[\mathrm{HCO}_{3}-\right]>\left[\mathrm{HSO}_{4}^{-}\right]$

假に、これを等しいと見ても

$$
\left[\mathrm{HSO}_{4}^{-}\right]=\sqrt{1.34 \times 10^{-14}}=1.2 \times 10^{-7}
$$

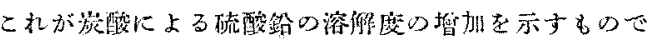

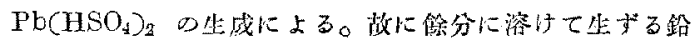
it,

$\left[\mathrm{Pb}^{++}\right]=\frac{1}{2} \times 1.2 \times 10^{-7}=0.6 \times 10^{-7}$ (报大倠儿相常する)

$$
\begin{aligned}
& \text { く" グラムイオン/l } \\
& \text { (馆際は小步る }
\end{aligned}
$$

これは硫酸鉛の純水一の答解度 $1.48 \times 10^{-4} \mathrm{~mol} / \mathrm{l}$ に比

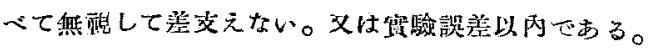




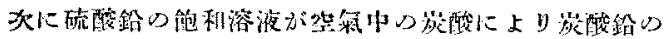

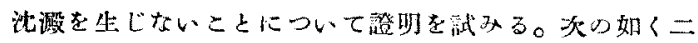
漛の證明をした。

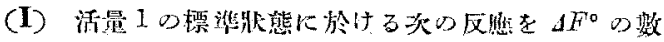
值から求める。

$$
\begin{aligned}
& \mathrm{Pb}+++\mathrm{H}_{2} \mathrm{CO}_{3}=\mathrm{PbCO}_{3}(\mathrm{~s})+2 \mathrm{H}^{+} \\
& \begin{array}{llll}
-5630 & -148810 & -149000 \quad 0
\end{array}
\end{aligned}
$$

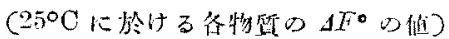

上の諸數做から， $A F^{\circ}=5440$

$\Delta F^{\circ}=5+40=-R T \ln K^{\circ} \mathfrak{y} \quad(1)$ 式の反憵の平

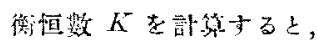

$$
K=\frac{\left[\mathrm{H}^{+}\right]^{2}}{[\mathrm{~Pb}++]\left[\mathrm{H}_{2} \mathrm{CO}_{3}\right]}=1 \times 10^{-4}
$$

今, $\mathrm{Pb}^{++}+\mathrm{H}_{2} \mathrm{CO}_{3}=\mathrm{PbCO}_{3}(\mathrm{~s})+2 \mathrm{H}^{+} \omega$ 反㑮 $\omega \mathrm{Pb}^{++}$

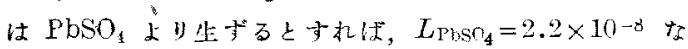

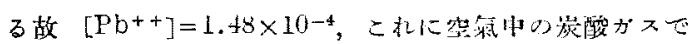
鸽和している炭酸が作月すると $\left.\mathrm{LH}_{2} \mathrm{CO}_{3}\right]=0.9 \times 10^{-5}$

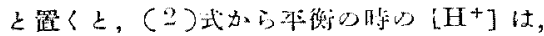

$\left[\mathrm{H}^{+}\right]^{2}=1 \times 10^{-4} \times 1.48 \times 10^{-4} \times 0.9 \times 10^{-5}$

$$
=1.33 \times 10^{-13}=13.3 \times 10^{-14}
$$

$\therefore\left[\mathrm{H}^{+}\right]=3.6 \times 10-7$ グラムイオン/l

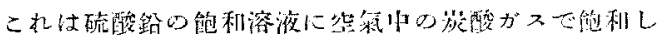

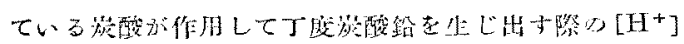
老與之吉。

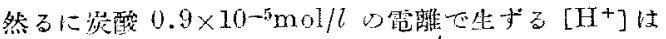

$$
\begin{aligned}
& K_{1}=3.5 \times 10^{-7}=\begin{array}{c}
{\left[\mathrm{H}^{+}\right]\left[\mathrm{HCO}_{3}^{-}\right] .} \\
{\left[\mathrm{H}_{2} \mathrm{CO}_{3}\right]}
\end{array} \frac{\left[\mathrm{H}^{+}\right]^{2}}{0.9 \times 10^{-5}} \\
& {\left[\mathrm{H}^{+}\right]^{2}=3.5 \times 10^{-7} \times 0.9 \times 10^{-5}=3.2 \times 10^{-12}}
\end{aligned}
$$

故に, $\left[\mathrm{H}^{+}\right]=1.8 \times 10^{-6}$ ダラムイホン $/ l$

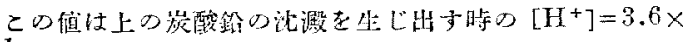
$I_{0-7}$ 上り大であるから, $\mathrm{PbCO}_{3}(\mathrm{~s})$ は纵じない。
(II) $\mathrm{Pb}+++\mathrm{H}_{2} \mathrm{OO}_{3} \rightleftarrows \mathrm{PbCO}_{3}(\mathrm{~S})+2 \mathrm{H}^{+}$

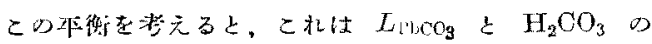
$K_{1}, K_{2}$ z加浗闪机る。

$$
\begin{aligned}
& {[\mathrm{Pb}++]\left[\mathrm{CO}_{3}--\right]=L_{14 \mathrm{CC}_{3}}, K_{1}=\frac{\left[\mathrm{H}^{+}\right]\left[\mathrm{HCO}_{3}\right]}{\left[\mathrm{H}_{2} \mathrm{CO}_{3}\right]},} \\
& K_{2}=\frac{\left[\mathrm{H}^{+}\right]\left[\mathrm{CO}_{3}--\right]}{\left[\mathrm{HCO}_{3}-\right]}
\end{aligned}
$$

これ第を組会わせて

$$
\begin{aligned}
& {\left[\mathrm{Pb}^{++}\right]=\frac{L}{K_{1}} K_{2}^{-} \frac{\left[\mathrm{H}^{+}\right]^{2}}{\left[\mathrm{H}_{2} \mathrm{CO}_{3}\right]}=\frac{1.5 \times 10^{-13}}{3.5 \times 10^{-7} \times 5 \times 10^{-11}}} \\
& \times \frac{\left[\mathrm{H}^{+}\right]^{2}}{\left[\mathrm{H}_{2} \mathrm{CO}_{3}\right]}=8600_{\left.\frac{\left[\mathrm{H}^{+}\right.}{2}\right]^{2}}^{\left[\mathrm{H}_{2} \mathrm{CO}_{3}\right]} \quad\left(L_{\mathrm{PbO} \mathrm{O}}=1.5 \times 10^{-13}\right)
\end{aligned}
$$

上例の如く $\mathrm{Pb}^{++}$は硫酸鉿上り生じているとす机ば， $\left[\mathrm{Pb}^{++}\right]=1.48 \times 10^{-4}$, 文 $\left[\mathrm{H}_{2} \mathrm{OO}_{3}\right]=0.9 \times 10^{-5}$ としてよ Wか下，

$$
\begin{aligned}
& {\left[\mathrm{H}^{+}\right]^{2}=\frac{1.48 \times 10^{-4} \times 0.9 \times 10^{-5}}{8.6 \times 10^{3}}=15.5 \times 10^{-14}} \\
& {\left[\mathrm{H}^{+}\right]=3.9 \times 10^{-7} \text { グ }}
\end{aligned}
$$

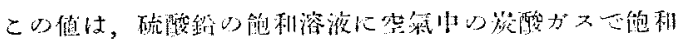
している蛙酸が作用して丁度 $\mathrm{PbCO}_{3}(\mathrm{~s})$ 在㘳じ姑める

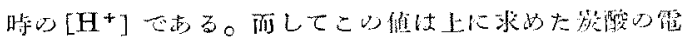

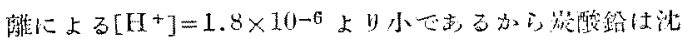

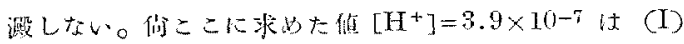
に於ける稙 $\left[\mathrm{H}^{+}\right]=3.6 \times 10^{-7}$ を绍んど一致している。

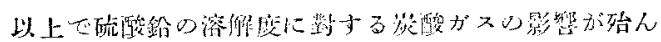

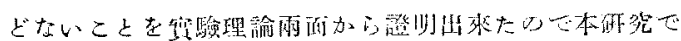
はこれを紫湤している。

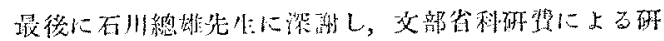
究をあること老特衙する。

$$
\text { 一文献 - }
$$

1)小沓, 日化, 68, 29(1947).

\section{酸化亞鉛に依る水蒸氣の吸着（第 3 報）}

宮原舆

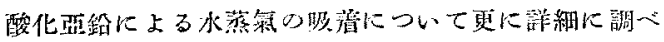

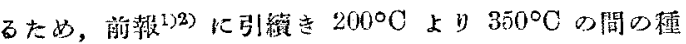

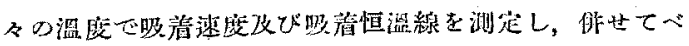

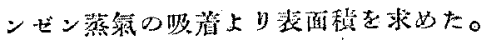

\section{實驗}

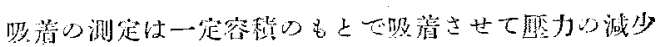

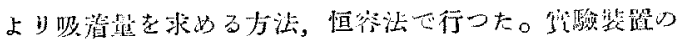

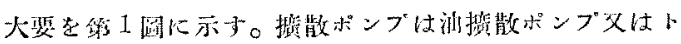

